\title{
Electroreduction of oxygen on a (100)-like polycrystalline gold surface in an alkaline solution containing $\mathrm{Pb}(\mathrm{II})$
}

\author{
Carlos Paliteiro*, Natércia Martins \\ Departamento de Química, Universidade de Coimbra, P-3049 Coimbra, Portugal
}

Received 12 June 1998

\begin{abstract}
In a previous work from this laboratory, it was shown that it is possible to electrochemically modify a polycrystalline surface of gold so that it behaves towards $\mathrm{O}_{2}$ reduction like the (100) gold plane. To check whether this similarity in behavior is due to the presence on the (100)-like surface of sufficiently large (100) spots, the process of the upd of $\mathrm{Pb}(\mathrm{II})$ was used in this work as a probe of the surface crystallographic orientations both in deaerated and in $\mathrm{O}_{2}$-saturated solutions. The observed cyclic voltammograms $(\mathrm{CV})$ and polarization curves were entirely different from those reported in the literature for a typical polycrystalline gold surface. The CV data were analyzed in an attempt to gain insight on the crystallography of the (100)-like surface. The influence of adsorbed lead on the electroreduction of oxygen in $1 \mathrm{M} \mathrm{NaOH}$ on the (100)-like surface was also scrutinised. It was found that the reduction is differently affected by adsorbed $\mathrm{Pb}(\mathrm{II})$ ions and by underpotential deposited $\mathrm{Pb}$ adatoms. Adsorbed $\mathrm{Pb}$ (II) do not change the reduction mechanism, it only alters the rate constant for $\mathrm{HO}_{2}^{-}$disproportionation, whereas the surface becomes able to reduce $\mathrm{O}_{2}$ to $\mathrm{OH}^{-}$without desorption of $\mathrm{HO}_{2}^{-}$to the solution bulk when modified by $\mathrm{Pb}$ adatoms. The details of the electroreduction of $\mathrm{O}_{2}$ and $\mathrm{HO}_{2}^{-}$are thoroughly discussed in relation to the surface processes underneath. Together with the CV data, they show that there are no significant (100) spots on the (100)-like surface and that this surface is structurally different from the gold (100) plane. (C) 1998 Elsevier Science Ltd. All rights reserved.
\end{abstract}

Keywords: Gold; Oxygen reduction; Lead upd; Modified surfaces; Electrocatalysis

\section{Introduction}

As showed recently [1], it is possible to electrochemically modify a polycrystalline gold surface (pc-Au) so that it behaves towards $\mathrm{O}_{2}$ reduction both in $\mathrm{HClO}_{4}$ and in alkaline solutions like a (100) plane, the most active surface found so far for the reaction in such media. In fact, in $1 \mathrm{M} \mathrm{NaOH}$ for example, the onset potential for the reduction on the modified surface (hereafter called ' 100 '- $\mathrm{Au}$ ) is $\approx 50 \mathrm{mV}$ more anodic than on pc-Au and the polarization curves show a maximum at $\approx 750 \mathrm{mV}$ vs. the reversible hydrogen electrode (RHE) where the current approaches the 4-electron level.

\footnotetext{
* Corresponding author.
}

It has been a challenge for us to understand why ' 100 '-Au has such a catalytic activity, since it may lead to the identification of reaction sites (or surface structures) that will allow the tailoring of surfaces with adequate activity and stability for $\mathrm{O}_{2}$ electroreduction. One may wonder, for example, whether the (100)-like behavior of the ' 100 '-Au surface is due to the presence on it of patches of the (100) plane. One experimental approach to this problem is to examine the surface directly by applying in-situ STM [2]. Another approach is to use the upd of metals as a probe, since such a process is quite sensitive to surface structure. The upd of lead is a convenient example of this process because it was studied in detail on pc-Au and $\mathrm{Au}$ single crystals (mainly in $\mathrm{HClO}_{4}$ ) so that a sort of atlas of lead upd spectra on most of the Au planes is available in the literature $[3,4]$; data on the electroreduction 
of $\mathrm{O}_{2}$ by pc-Au modified by lead upd are also available [5-9]. Since all this work is a good basis for comparison, we decided to look at the upd of lead on the ' 100 '-Au surface and to investigate the influence of such deposit upon the reduction of $\mathrm{O}_{2}$ and of $\mathrm{HO}_{2}^{-}$in $1 \mathrm{M} \mathrm{NaOH}$. The results obtained, which this paper reports and discusses, appear to show that the '100'Au surface is structurally different from the (100) gold plane.

\section{Experimental}

The polycrystalline Au electrode used in this work was a disc of $99.99 \% \mathrm{Au}$ from Johnson Matthey with a geometric area of $0.150 \mathrm{~cm}^{2}$ and formed as a RDE with Teflon. The disc was polished with diamond paste to a $0.25 \mu \mathrm{m}$ finish, sonicated in an ultrasonic bath and carefully cleaned with AnalaR ethanol and pyrodistilled water. The potential of this pc-Au surface was first scanned at $50 \mathrm{mVs}^{-1}$ in a deaerated $0.5 \mathrm{M} \mathrm{H}_{2} \mathrm{SO}_{4}$ solution between the onsets of $\mathrm{H}_{2}$ and of $\mathrm{O}_{2}$ evolution, until the well-known stable cyclic voltammogram $(\mathrm{CV})$ of gold in this acid solution was observed. A potential of $-300 \mathrm{mV}$ vs. RHE was then applied for $10 \mathrm{~min}$ with the RDE rotating at $10 \mathrm{rps}$. This applied potential assured a current density of about $670 \mu \mathrm{A} \mathrm{cm} \mathrm{cm}^{-2}$. After this pretreatment, the electrode was carefully washed with pyrodistilled water and put in a desiccator. Four days later the CVs and the polarization curves obtained on the pretreated electrode in a $1 \mathrm{M}$ $\mathrm{NaOH}$ solution by scanning the potential between $-100 \mathrm{mV}$ and $1000 \mathrm{mV}$ (i.e. by keeping the upper potential limit below $1150 \mathrm{mV}$, which is the stability anodic limit of ' 100 '-Au) were characteristic of a ' 100 '$\mathrm{Au}$ surface [1]. We measured the real area of the polished pc-Au surface using Wood's method [10] (surface roughness $=1.4$ ), but the relationship between this area and the real area of the final ' 100 '-Au surface is uncertain.

$\mathrm{HClO}_{4}, \mathrm{NaOH}$ and $\mathrm{PbF}_{2}$ were of proanalysis or AnalaR quality. All solutions were prepared with pyrodistilled water. General purpose $30 \% \quad \mathrm{H}_{2} \mathrm{O}_{2}$ was distilled following the procedure given by Perrin et al. [11]; the fraction of pure $\mathrm{H}_{2} \mathrm{O}_{2}$ was collected and diluted with pyrodistilled water to obtain a $2.5 \mathrm{M}$ stock solution. The $\mathrm{H}_{2} \mathrm{O}_{2}$ solutions for the experiments reported below were prepared from this stock solution just before use and the actual concentration of $\mathrm{H}_{2} \mathrm{O}_{2}$ was determined by titration with standardized $\mathrm{KMnO}_{4}$.

An electrochemical cell with three-separated compartments was used. Solutions in this cell were saturated with high-purity $\mathrm{O}_{2}$ (type $\mathrm{C}$ ) or argon (N46) from Air Liquide. The potential of the Au electrode was controlled by a Pine Instruments AFRDE4 potentiostat and measured against a $1 \mathrm{M} \mathrm{NaOH} \mathrm{Hg} / \mathrm{HgO}$ electrode or a standard calomel electrode (SCE); it is referred hereafter to the reversible hydrogen electrode (RHE). Working electrode rotation was provided by a Pine Instruments AFMSRX rotator. A glassy carbon rod was used as the counter electrode. All the experimental curves were recorded on a Philips PM $8043 X_{-}$ $Y$ recorder.

\section{Results}

\subsection{UPD of lead on '100'-Au}

Fig. 1(a) and (b) show the upd spectra of $1 \mathrm{mM} \mathrm{Pb}$ (II) recorded on ' 100 '- $\mathrm{Au}$, respectively in $0.01 \mathrm{M}$ $\mathrm{HClO}_{4}$ and in $1 \mathrm{M} \mathrm{NaOH}$. Although the predominant $\mathrm{Pb}$ (II) species are hydrated $\mathrm{Pb}^{2+}$ in the acid solution and $\mathrm{HPbO}_{2}^{-}$in the alkaline, the shapes of the two spectra are similar and quite different from those reported for the $(100)[3,5,6]$ and the pc-Au [12] surfaces. It is known that, on the Au surfaces and in acid, $\mathrm{Pb}$ (II) deposits at underpotential as a totally discharged $\mathrm{Pb}$ atom [3]. Given the similarity of the spectra, it is probable that the same happens in alkaline.

In $1 \mathrm{M} \mathrm{NaOH}+1 \mathrm{mM} \mathrm{Pb}$ (II), the upd process starts at $600 \mathrm{mV}$, the upd spectrum is dominated by a broad peak at $\approx 450 \mathrm{mV}$, followed by a much smaller feature at $\approx 370 \mathrm{mV}$ and a well defined peak at $300 \mathrm{mV}$ (cf. Fig. 1(b)).

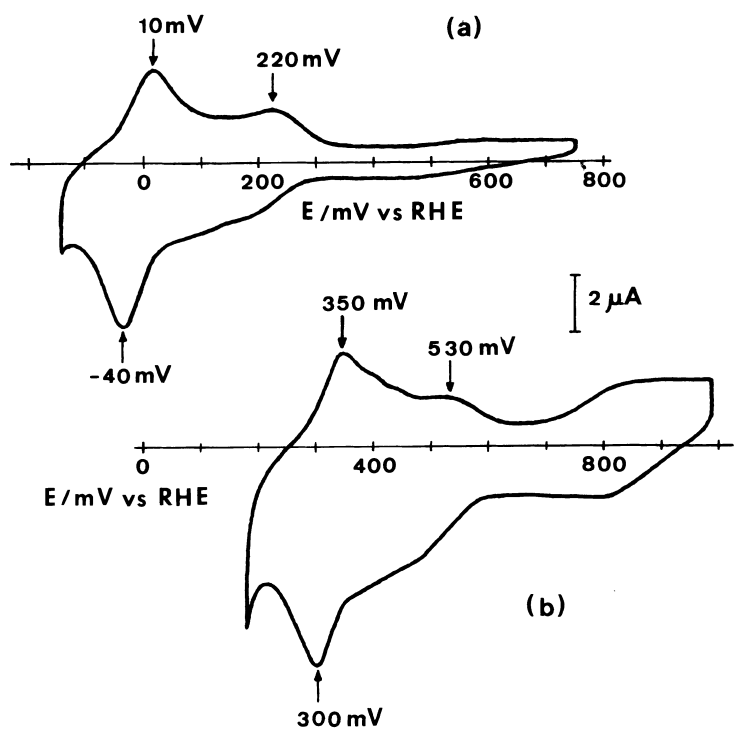

Fig. 1. CVs recorded at $20 \mathrm{mV} \mathrm{s}^{-1}$ and rotation rate of $9 \mathrm{~s}^{-1}$ on a ' 100 '-Au surface in argon-saturated (a) $0.01 \mathrm{M}$ $\mathrm{HClO}_{4}+1 \mathrm{mM} \mathrm{Pb}$ (II) and (b) $1 \mathrm{M} \mathrm{NaOH}+1 \mathrm{mM} \mathrm{Pb}$ (II) solutions. 


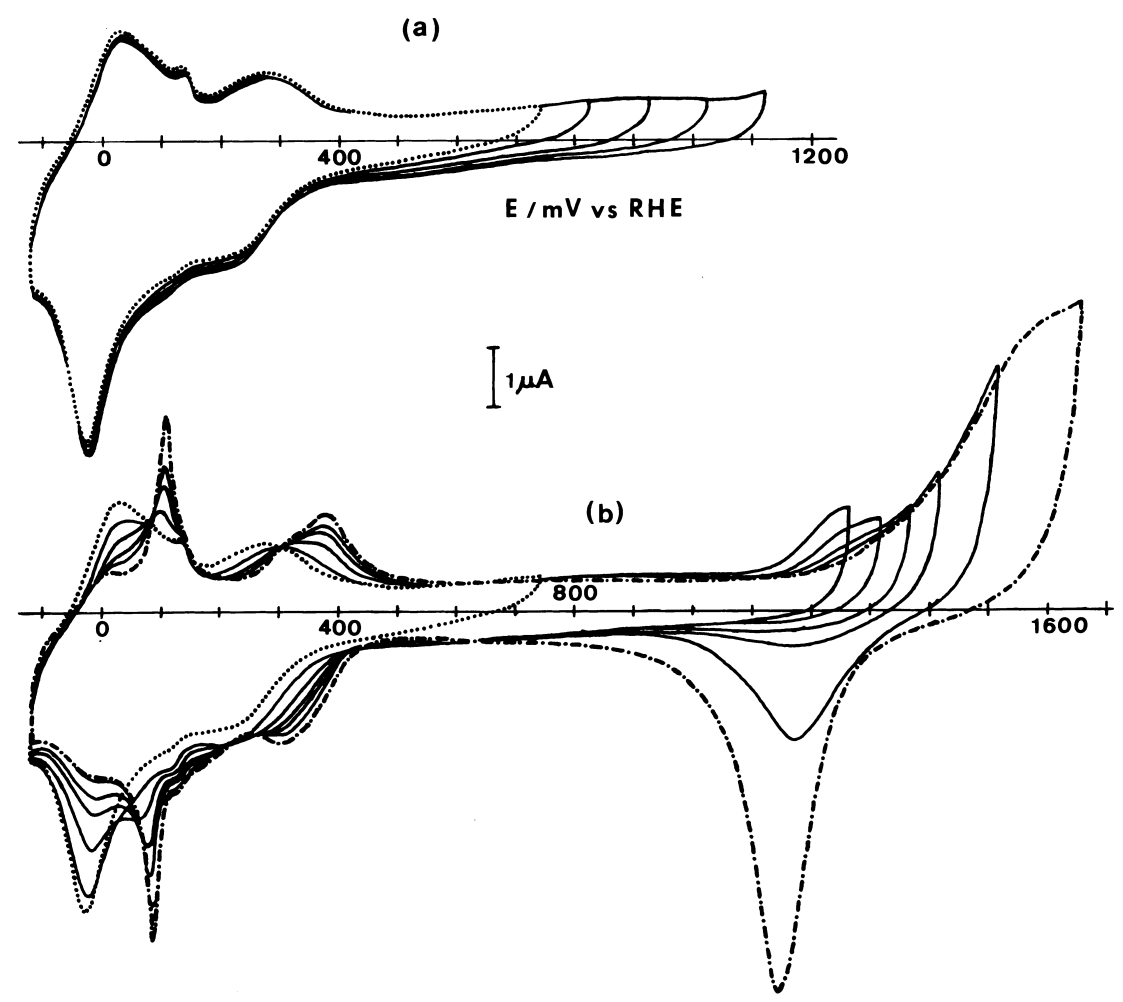

Fig. 2. (a) the $\mathrm{CV}$ of the ' 100 '- $\mathrm{Au}$ surface in a deaerated $0.01 \mathrm{M} \mathrm{HClO}_{4}+1 \mathrm{mM} \mathrm{Pb}$ (II) solution is reproducible provided that the higher vertex potential is within the potential range of ' 100 '-Au stability, (b) increasing the higher vertex potential beyond $\cong 1150$ $\mathrm{mV}$, gradually changes the $\mathrm{CV}$ of ' $100^{\prime}$ '-Au to the $\mathrm{CV}$ of pc-Au; ( . .) initial $\mathrm{CV},(-\cdot-)$ final $\mathrm{CV}$; scan rate $20 \mathrm{mV} \mathrm{s}^{-1}$; rotation rate $9 \mathrm{~s}^{-1}$.

The potentials of bulk deposition, $E_{\mathrm{bd}}$, for $\mathrm{C}_{\mathrm{Pb}(\mathrm{II})}=1 \mathrm{mM}$ were calculated. We found $-105 \mathrm{mV}$ in $0.01 \mathrm{M} \mathrm{HClO}_{4}$ (activity $a\left(\mathrm{~Pb}^{2+}\right)=6.6 \times 10^{-4} \mathrm{M}$ and $E^{0}\left(\mathrm{~Pb}^{2+} / \mathrm{Pb}\right)=-0.126 \mathrm{~V}$ [11]) and $210 \mathrm{mV}$ in $1 \mathrm{M}$ $\mathrm{NaOH}\left(a\left(\mathrm{HPbO}_{2}^{-}\right)=2.5 \times 10^{-4} \mathrm{M}\right.$ and $E^{0}\left(\mathrm{HPbO}_{2}^{-} /\right.$ $\mathrm{Pb})=-0.54 \mathrm{~V}[13])$. These values agree well with those experimentally observed. Fig. 1 also shows that both $E_{\mathrm{bd}}$ and the potential of each peak of the upd spectrum shift $340 \mathrm{mV}$ as the $\mathrm{pH}$ goes from 2 to 14 . This $\mathrm{pH}$ independence of the shift of the potential of each peak as $\mathrm{pH}$ changes is a consequence of $\mathrm{Pb}(\mathrm{II})$ upd as a neutral atom and leads to the same peak separation $(220 \mathrm{mV})$ at $\mathrm{pH} 2$ and at $\mathrm{pH} 14$ [3].

Upon continuous scanning, a small anodic peak develops at $140 \mathrm{mV}$ in the cyclic voltammogram (CV) of Fig. 1(a) and the peak at $220 \mathrm{mV}$ may shift to 280 $\mathrm{mV}$ (cf. Fig. 2(a)).

We previously reported [1] that ' 100 '-Au gradually changes to pc-Au as the potential is cycled to increasingly anodic values beyond the stability limit $(\approx 1150$ $\mathrm{mV}$ ) of the ' $100-\mathrm{Au}$ ' surface. It was not surprising, therefore, to observe that the CV recorded on ' 100 '- $\mathrm{Au}$ in $0.01 \mathrm{M} \mathrm{HClO}_{4}+1 \mathrm{mM} \mathrm{Pb}^{2+}$ changes to the $\mathrm{CV}$ characteristic of a pc-Au surface in the same solution [11] as '100'-Au changes to pc-Au (cf. Fig. 2(a) and (b)). The overall features of the pc-Au CV reveal a somewhat disturbed surface (in the context of what was observed by Hamelin et al. [11]).

\subsection{Reduction of $\mathrm{O}_{2}$ on ' 100 '- $\mathrm{Au}$ in a $1 \mathrm{M}$ $\mathrm{NaOH}+\mathrm{Pb}(\mathrm{II})$ solution}

The RDE polarization curves for $\mathrm{O}_{2}$ reduction on ' 100 '- $\mathrm{Au}$ recorded in $1 \mathrm{M} \mathrm{NaOH}$ containing $\mathrm{Pb}(\mathrm{II})$ and restricting the lower potential limit to the onset of lead bulk electrodeposition, are shown in Fig. 3(b). Although they will be further discussed in Section 4.2 in relation to the curves in Fig. 3(a), we stress already here that, relatively to the polarization curves recorded in the absence of $\mathrm{Pb}(\mathrm{II})$, (i) the current intensity maximum decreases faster as the rotation rate increases, (ii) at a given rotation rate, the current intensity decrease below the current intensity maximum potential is slower and (iii) beyond $550 \mathrm{mV}$, the current intensity increases rapidly up to the 4-electron level.

The Koutecky-Levich (K-L) $I^{-1}$ vs. $\omega^{-0.5}$ plots (where $\omega$ is the rotation rate) are straight lines (cf. Fig. 4), whereas the plots $I^{0.5}$ vs. $I \omega^{-0.5}$ and $I^{2}$ vs. 


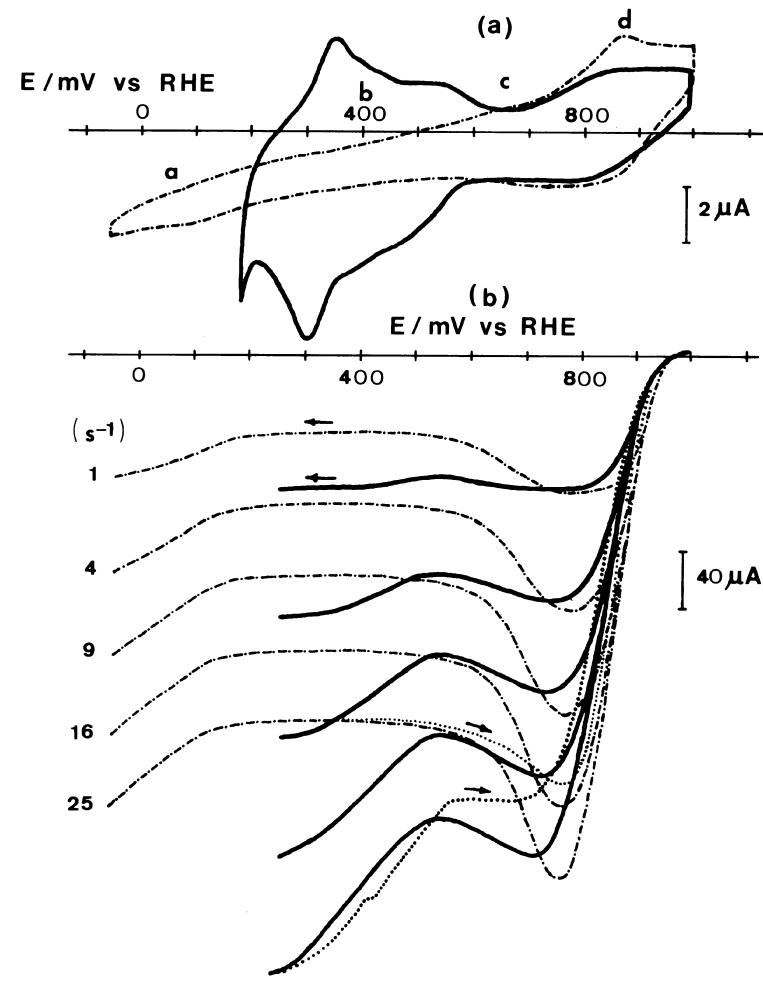

Fig. 3. (a) CVs recorded at $20 \mathrm{mV} \mathrm{s}^{-1}$ on a ' 100 '-Au surface in an argon-saturated $1 \mathrm{M} \mathrm{NaOH}$ solution and (b) polarization curves recorded at $10 \mathrm{mV} \mathrm{s}^{-1}$ on ' 100 '- $\mathrm{Au}$ in an $\mathrm{O}_{2}$-saturated $1 \mathrm{M} \mathrm{NaOH}$ solution; solutions with (- - ) and without (-.-) $1 \mathrm{mM} \mathrm{Pb(II).}$

$I \omega^{-0.5}$ are curved (cf. Fig. 5(a) and (b)). As mentioned in Ref. [14], these two plots give a straight line if the reaction order $(\mathrm{m})$ is, respectively, 2 and 0.5 . They are mathematically equivalent to the more frequently used $I^{-0.5}$ vs. $I^{0.5} \omega^{-0.5}$ plot for $m=2$ and $I^{-2}$ vs. $I^{-1} \omega^{-0.5}$ plot for $m=0.5$; contrarily to them, however, they are generally able to discriminate between reaction orders.

The electroreduction of $\mathrm{O}_{2}$ on ' 100 '- $\mathrm{Au}$ in a $1 \mathrm{M}$ $\mathrm{NaOH}+\mathrm{Pb}(\mathrm{II})$ solution is therefore a first order reaction. From the inverse of the slopes of the $\mathrm{I}^{-1}$ vs. $\omega^{-0.5}$ plots, the number of electrons, $n$, exchanged per $\mathrm{O}_{2}$ molecule reacted was calculated from Eq. (1) [15]:

(slope) $)^{-1}=0.62 n F A D^{2 / 3} v^{-1 / 6} C$,

where $F$ is the Faraday, $A$ is the electrode area, $D$ and $C$ are, respectively, the diffusion coefficient and the concentration of the reacting species in $1 \mathrm{M} \mathrm{NaOH}$ and $v$ is the kinematic viscosity of a $1 \mathrm{M} \mathrm{NaOH}$ solution, with $F=96487 \mathrm{C} \mathrm{mol}^{-1}, D\left(\mathrm{O}_{2}\right)=1.65 \times 10^{-5}$ $\mathrm{cm}^{2} \mathrm{~s}^{-1}$ [16], $v=1.0624 \times 10^{-2} \mathrm{~cm}^{2} \mathrm{~s}^{-1}$ [17] and $C\left(\mathrm{O}_{2}\right)=8.4 \times 10^{-7} \mathrm{~mol} \mathrm{~cm}^{-3}$ [18] and is shown in Fig. 6 relatively to the electrode potential. Below 600

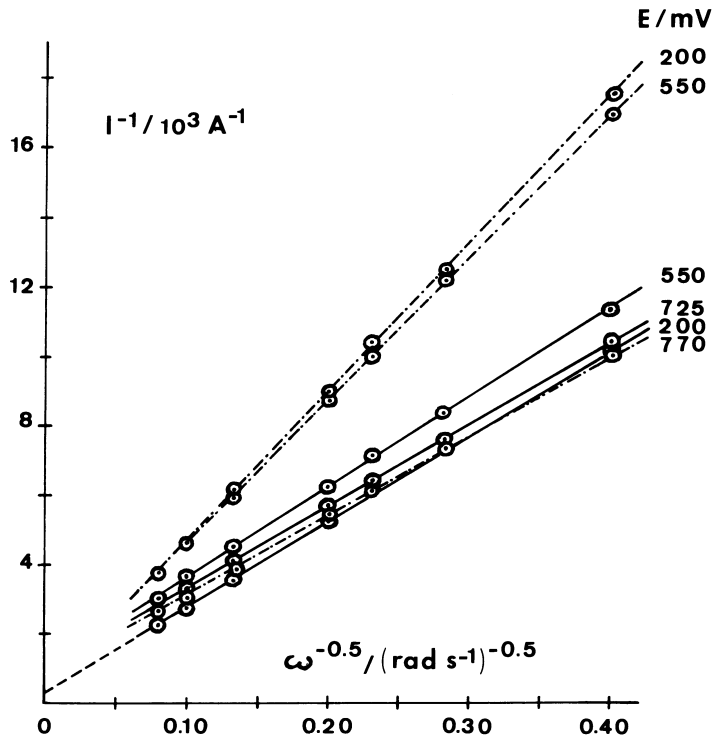

Fig. 4. Koutecky-Levich $I^{-1}$ vs. $\omega^{-0.5}$ plots obtained from the polarization curves of Fig. 3(b); $1 \mathrm{M} \mathrm{NaOH}$ solution with $(-$ ) and without $(-\cdot-) \mathrm{Pb}(\mathrm{II})$.

$\mathrm{mV}, n$ is always close to 4 on the ' 100 '- $\mathrm{Au}$ surface immersed in the $\mathrm{Pb}(\mathrm{II})$ solution, therefore much higher than on ' 100 '- $\mathrm{Au}$ in the absence of $\mathrm{Pb}$ (II). Below $\approx 250$ $\mathrm{mV}$, the intercepts of the K-L lines are close to the origin.

From the potential of the current intensity maximum down to $550 \mathrm{mV}$, the Levich plots for ' 100 '-Au in the $\mathrm{NaOH}+\mathrm{Pb}$ (II) solution curve down as the rotation rate increases (cf. Fig. 7); at the potential of the current intensity maximum, the curvature is higher than that found in the absence of $\mathrm{Pb}(\mathrm{II})$ at the same potential.

The rotation independent Tafel slope (cf. Fig. 8) is practically unaltered when $\mathrm{Pb}$ (II) is added to the $1 \mathrm{M}$ $\mathrm{NaOH}$ solution; it is -60 and $-65 \mathrm{mV} \mathrm{dec}{ }^{-1}$ for, respectively, in the absence and in the presence of $\mathrm{Pb}(\mathrm{II})$. Like the other Tafel slopes reported in this work, these slopes were obtained from a $E$ vs. $\log \left(I / I_{\mathrm{L}}-I\right)$ plot (where $I$ and $I_{\mathrm{L}}$ mean, respectively, the disc current intensity and the limiting disc current intensity).

\subsection{Reduction and oxidation of $\mathrm{HO}_{2-}$ on '100'-Au in a $1 \mathrm{M} \mathrm{NaOH}+\mathrm{Pb}(\mathrm{II})$ solution}

Fig. 9 compares polarization curves obtained on ' 100 '-Au immersed in an argon-saturated $1 \mathrm{M}$ $\mathrm{NaOH}+1 \quad \mathrm{mM} \quad \mathrm{HO}_{2}^{-}$solution with and without $\mathrm{Pb}(\mathrm{II})$. As expected from the data collected for the reduction of $\mathrm{O}_{2}$, the current intensity maximum at 835 $\mathrm{mV}$ for $\mathrm{HO}_{2}^{-}$reduction decreases when $\mathrm{Pb}(\mathrm{II})$ is present in solution. Below $835 \mathrm{mV}$, the current intensity 

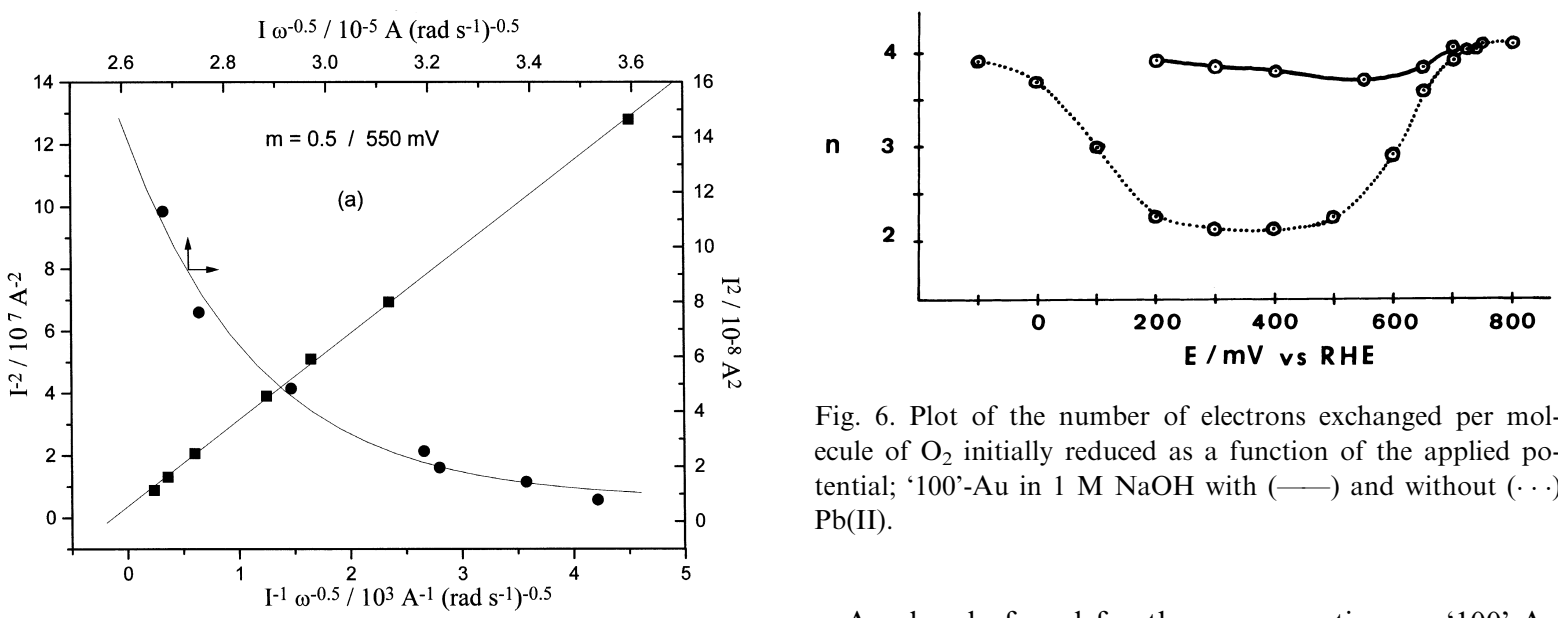

Fig. 6. Plot of the number of electrons exchanged per molecule of $\mathrm{O}_{2}$ initially reduced as a function of the applied potential; ' 100 '-Au in $1 \mathrm{M} \mathrm{NaOH}$ with $(-)$ and without $(\cdots)$ $\mathrm{Pb}(\mathrm{II})$.

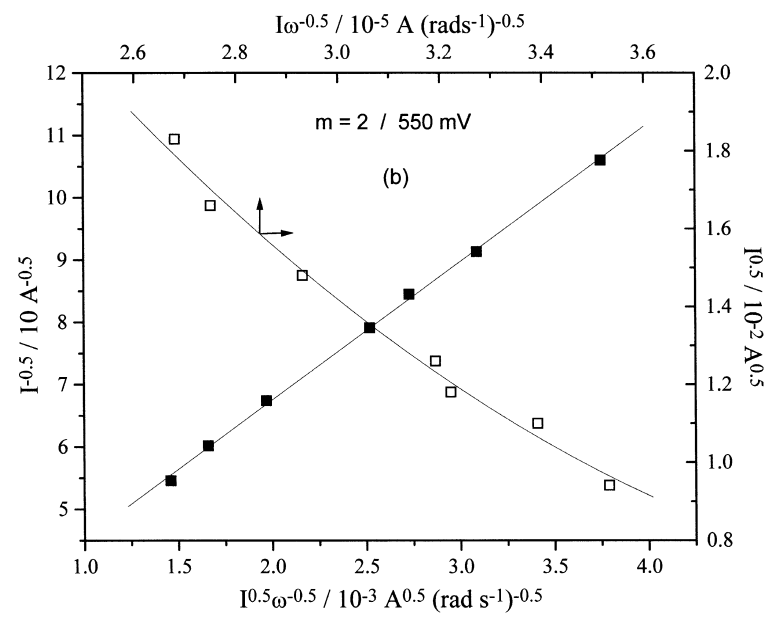

As already found for the same reaction on ' 100 '-Au in the absence of $\mathrm{Pb}(\mathrm{II})$ [1], for $\mathrm{HO}_{2}^{-}$reduction when $\mathrm{Pb}$ (II) is present, (i) the K-L $I^{-1}$ vs. $\omega^{-0.5}$ plots are straight lines, which, together with the curved $I^{0.5}$ vs. $I \omega^{-0.5}$ and $I^{2}$ vs. $I \omega^{-0.5}$ plots, means that the reaction is first order; the lines are parallel to each other with a slope corresponding to 2 electrons per $\mathrm{HO}_{2}^{-}$ reacted calculated from Eq. (1) with $D\left(\mathrm{HO}_{2}^{-}\right)=8.5 \times 10^{-6} \quad \mathrm{~cm}^{2} \quad \mathrm{~s}^{-1} \quad[19] \quad$ and $C\left(\mathrm{HO}_{2}^{-}\right)=1.49 \times 10^{-6} \mathrm{~mol} \mathrm{~cm}{ }^{-3}$, (ii) the rotation independent Tafel slope is $-30 \mathrm{mV} \mathrm{dec}^{-1}$, (iii) the Levich plot at $835 \mathrm{mV}$ curves down corresponding to a K-L plot that does not cross the origin.

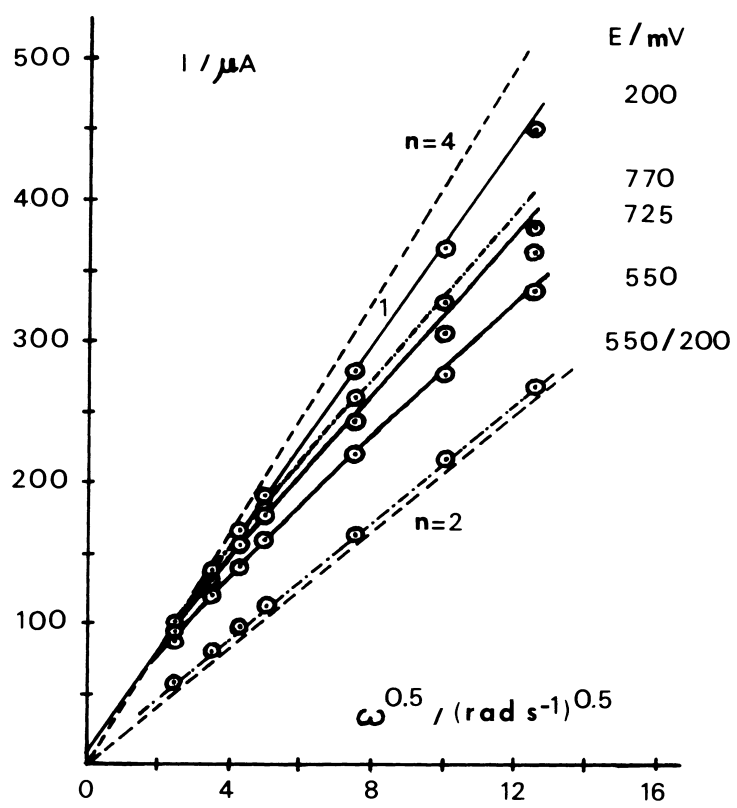

Fig. 7. Levich plots obtained from the polarization curves of Fig. 3(b); $1 \mathrm{M} \mathrm{NaOH}$ solution with (- - ) and without (.-) $\mathrm{Pb}(\mathrm{II})$ 


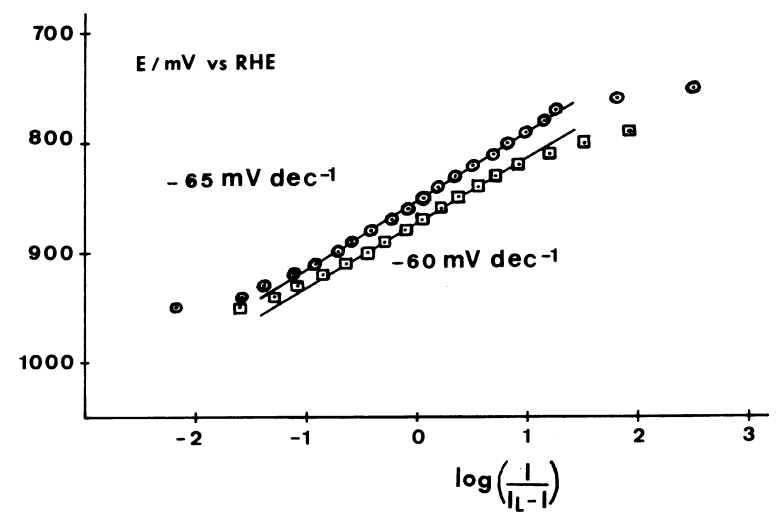

Fig. 8. Tafel slopes obtained from the polarization data in Fig. 3(b); $1 \mathrm{M} \mathrm{NaOH}$ solution with $(-\odot-)$ and without $\mathrm{Pb}$ (II) (square with dot).

The observed current intensity for $\mathrm{HO}_{2}^{-}$oxidation on ' 100 '-Au in $1 \mathrm{M} \mathrm{NaOH}$ is also smaller when $\mathrm{Pb}$ (II) is present in solution. The $\mathrm{K}-\mathrm{L}$ plot at $1050 \mathrm{mV}$ is a straight line that crosses the origin, which means that the oxidation of $\mathrm{HO}_{2}^{-}$is diffusion-controlled at that potential. From the slope of that line, the above-mentioned value of $D\left(\mathrm{HO}_{2}^{-}\right)$was calculated by assuming $n=2$ in Eq. (1). Less than this number of electrons was found below $1000 \mathrm{mV}$, probably due to a current intensity decrease as a consequence of the simultaneous reduction of the $\mathrm{O}_{2}$ produced during the oxidation of $\mathrm{HO}_{2}^{-}$.

\section{Discussion}

\subsection{On the nature of the '100'-Au surface}

It is not possible to match the observed stripping of lead from ' 100 '-Au with any of the stripping spectra of lead for the $\mathrm{Au}$ planes (including (100)) in a $0.01 \mathrm{M}$ $\mathrm{HClO}_{4}+1 \mathrm{mM} \mathrm{Pb}{ }^{2+}$ reported by Hamelin et al. (cf. Fig. 1(a) with Fig. 1 of Ref. [3]). We tried, therefore, to rationalise the individual features of the $\mathrm{CV}$ of Fig. 1(a)) since only for the upd and stripping peaks of lead in $0.01 \mathrm{M} \mathrm{HClO}_{4}$ there are some data available.

As far as we know, the broad peak at $220 \mathrm{mV}$ was never reported in literature. It may be related to the

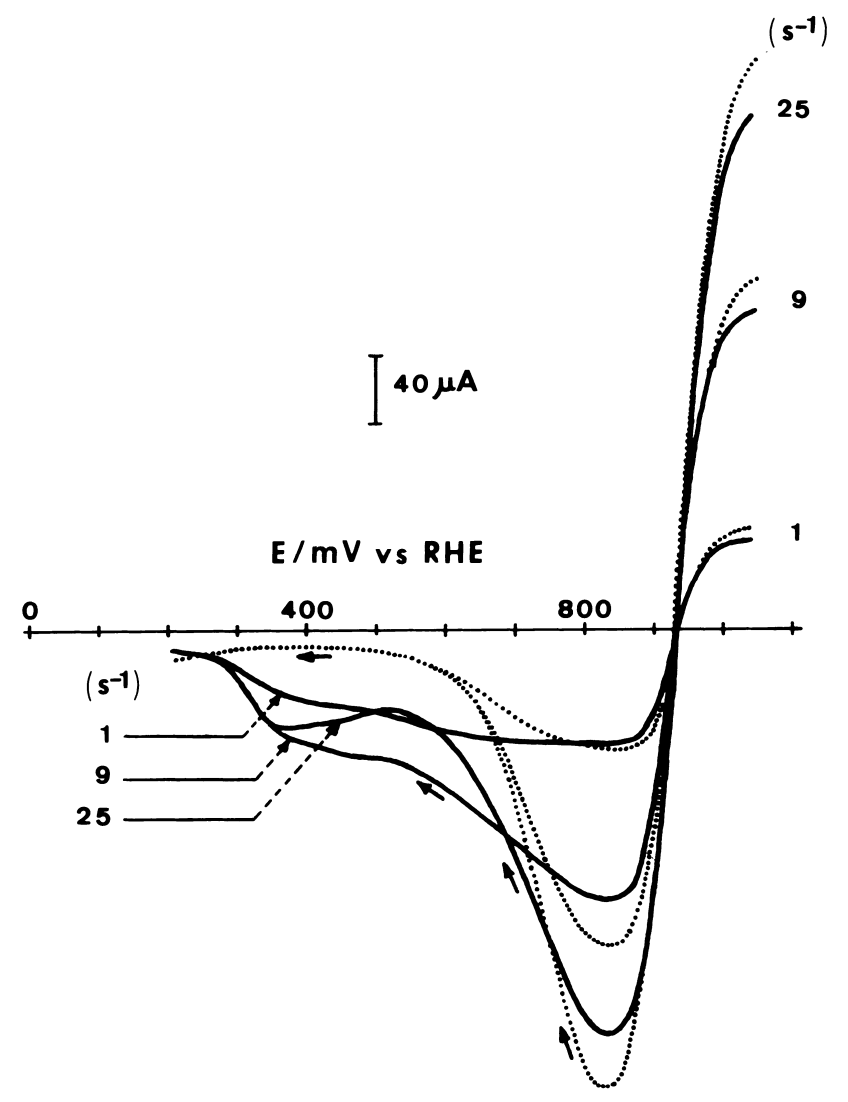

Fig. 9. Polarization curves recorded at $10 \mathrm{mV} \mathrm{s}^{-1}$ on a ' 100 '-Au surface in an argonsaturated $1 \mathrm{M} \mathrm{NaOH}+1.5 \mathrm{mM} \mathrm{HO}_{2}^{-}$solution with (—) and without $(\cdots) 1 \mathrm{mM} \mathrm{Pb}(\mathrm{II})$. 
stripping of lead from narrow terraces on a surface about $18^{\circ}$ from the (100) plane on the (100)-(110) zone [20]. The stripping peak at $10 \mathrm{mV}$ is common to pc-Au and to ' 100 '-Au (cf. Fig. 2(b)), although smaller in the CV of pc-Au. In her work on lead upd on pc$\mathrm{Au}$ from a $0.01 \mathrm{M} \mathrm{HClO}_{4}+1 \mathrm{mM} \mathrm{Pb}^{2+}$ solution [11], this peak was ascribed by Hamelin to lead deposition on the (311) plane. Later, she related the peak at $\approx 10$ $\mathrm{mV}$ observed in the $\mathrm{CV}$ of (311) in the same solution to the existence of terraces with (111) orientation and less than four atoms wide [4]. The peak at $\approx 140 \mathrm{mV}$ may also be related to the (311) plane (cf. Fig. 6 of Ref. [4]). But the CV of ' 100 '-Au in contact with $\mathrm{Pb}(\mathrm{II})$ does not show the large and reversible peak centered at $\approx 360 \mathrm{mV}$ observed in the $\mathrm{CV}$ of (311) and ascribed by Hamelin to the occurrence of monoatomic steps with (100) orientation (cf. Fig. 1(a) with Fig. 6 in Ref. [4]). Even if it is accepted that the ' 100 '-Au surface expose (311) planes to the electrolyte, their amount does not appear to be significant. In fact, (i) the only common features between the $\mathrm{CV}$ of (311) and the CV of ' 100 '- $\mathrm{Au}$ in $0.01 \mathrm{M} \mathrm{HClO}_{4}+1 \mathrm{mM}$ $\mathrm{Pb}^{2+}$ are the peaks at $10 \mathrm{mV}$ and at $140 \mathrm{mV}$; additionally, a peak at $220 \mathrm{mV}$ is observed with ' 100 '-Au but not with (311), whereas a peak at $\approx 400 \mathrm{mV}$, which is a characteristic feature of the (311) CV [4], is absent in the $\mathrm{CV}$ of ' 100 '- $\mathrm{Au}$, (ii) the ' 100 '-Au surface is more active for $\mathrm{O}_{2}$ and for $\mathrm{HO}_{2}^{-}$electroreduction than (311) [21], (iii) the shapes of the polarization curves for $\mathrm{O}_{2}$ and for $\mathrm{HO}_{2}^{-}$electroreduction on '100'-Au [1] and on (311) [21] are different. Instead, the polarization curves for $\mathrm{O}_{2}$ reduction on ' 100 '-Au are entirely similar to those recently reported for (100) [22], (iv) for (311), the $\mathrm{HO}_{2}^{-}$reduction current intensity in the potential range of the maximum was reported to be smaller in the cathodic scan than in the anodic scan [20] whereas, for ' 100 '-Au, the inverse has always been observed to be true. This difference in hysteresis may indicate that different surface species are present on the two surfaces.

It also appears that the (100)-like behavior of ' 100 '$\mathrm{Au}$ towards $\mathrm{O}_{2}$ reduction is not due to the presence on the surface of sufficient large number of areas with (100) orientation. Indeed, (i) the CV of ' 100 '- $\mathrm{Au}$ does not show any of the five peaks associated with the stripping of lead from the (100) surface [20]. Instead and as discussed above, it shows features that may be related to the presence on the ' 100 '-Au surface of planes at $25^{\circ}$ (the (311) plane) and at $18^{\circ}$ from (100) on the (100)-(110) zone (cf. Fig. 2 of Ref. [20]). However, the peak at $\approx 400 \mathrm{mV}$, always present on these planes and ascribed to the stripping of lead from steps [20], is never observed in the CV of ' 100 '-Au, (ii) as we demonstrate below, the behavior towards the electroreduction of $\mathrm{O}_{2}$ of the ' 100 '-Au surface in the presence of $\mathrm{Pb}(\mathrm{II})$ differs entirely from that reported in the literature for $(100)$ in the same conditions $[6,23]$.

\subsection{Analysis of $\mathrm{O}_{2}$ reduction on ' 100 '- $\mathrm{Au}$ in a $1 \mathrm{M}$ $\mathrm{NaOH}+\mathrm{Pb}(\mathrm{II})$ solution}

In a previous work from this laboratory [1], the discussion of the surface electrochemistry of ' 100 '-Au was based on the electrochemical activity of four surface species (which we referred to by the letters a-d) and these species were related to the way how the surface deals with $\mathrm{HO}_{2}^{-}$below $950 \mathrm{mV}$. The potential ranges of species a to $\mathrm{d}$ are indicated in Fig. 3(a), which also compares the CVs of ' 100 '- $\mathrm{Au}$ in the absence and in the presence of $\mathrm{Pb}(\mathrm{II})$. The $\mathrm{CV}$ in the absence of $\mathrm{Pb}$ (II) is tilted. Such tilt is not due to the reduction of residual $\mathrm{O}_{2}$ in the solution, since no change of the current intensity was observed when the electrode was rotated at a significantly high rate. A similar tilted CV was also reported for the (100) plane in alkaline solution [22, 24, 25].

Fig. 3(a) shows that, in the presence of $\mathrm{Pb}(\mathrm{II})$, the following changes occur in the CV of ' 100 '-Au:

(i) In the potential range of species $d(750-950 \mathrm{mV})$ and $\mathrm{c}(600-750 \mathrm{mV})$, the charge under the anodic and the cathodic peak decreases. Species d results from $\mathrm{OH}^{-}$adsorption with full charge transfer and was called $\mathrm{AuOH}$ [1]. If the potential of zero charge (pzc) of ' 100 '- $\mathrm{Au}$ is close to the pzc of pc-Au ( $\approx 700 \mathrm{mV}[6])$, above this potential and in the presence of $\mathrm{HPbO}_{2}^{-}$the adsorption of this anion is also possible. We suggest that the discharged $\mathrm{OH}$ has to compete with $\mathrm{HPbO}_{2}^{-}$ for ' 100 '-Au and that, as a result, a certain amount of negative charge builds on this surface. It is also reasonable to accept that this amount of charge decreases as the potential is made more cathodic and the onset of the upd process is approached, due to a partial discharge of the adsorbed $\mathrm{HPbO}_{2}^{-}$together with the decrease of its coverage.

(ii) Below $600 \mathrm{mV}$, the charge under the $\mathrm{CV}$ increases due to the upd and to the stripping of lead. These processes occur within the potential regions of species $\mathrm{b}(300-550 \mathrm{mV})$ and of species a (50-250 mV).

There are, therefore, essentially two processes that we expect may influence the reduction of $\mathrm{O}_{2}$ on '100'$\mathrm{Au}$ in $1 \mathrm{M} \mathrm{NaOH}$ in the presence of $\mathrm{Pb}(\mathrm{II})$ : the adsorption of $\mathrm{HPbO}_{2}^{-}$and the deposition of $\mathrm{Pb}$ adatoms.

\subsubsection{Potential range of $\mathrm{Pb}(\mathrm{II})$ adsorption}

The Levich plots for $\mathrm{HO}_{2}^{-}$reduction and for $\mathrm{O}_{2}$ reduction on ' 100 '-Au at the potential of the maximum $(\approx 800 \mathrm{mV})$ curve down as the rotation rate increases. This was taken in Ref. [1] as an indication that, at that potential, $\mathrm{HO}_{2}^{-}$is disproportionated and that the $\mathrm{HO}_{2}^{-}$ 'reduction' current is in fact a catalytic current result- 
ing from the recycling of the $\mathrm{O}_{2}$ produced in the disproportionation reaction. It was also proposed that, whereas species $d$ promotes this reaction (by favoring $\mathrm{HO}_{2}^{-}$adsorption), change from species d to c decreases its rate constant and, consequently, gives rise to a decrease of the measured current intensity in the potential region of species c. This proposition implies that adsorption (not coadsorption) of $\mathrm{HO}_{2}^{-}$on the ' 100 '-Au surface already covered by adsorbed $\mathrm{OH}$ species is assumed to occur. The basis for this assumption is the following reasoning: in experiments involving a deaerated $1 \mathrm{M} \mathrm{NaOH}+\mathrm{HO}_{2}^{-}$solution, $\mathrm{HO}_{2}^{-}$is directly available to interact with the electrode after diffusion from solution, whereas in experiments involving an $\mathrm{O}_{2}$-saturated $1 \mathrm{M} \mathrm{NaOH}$ solution, the only $\mathrm{HO}_{2}^{-}$available is that produced by the reduction of $\mathrm{O}_{2}$. Nevertheless and as shown by the close similarity of the shape of the respective polarization curves, the $\mathrm{O}_{2}$ reduction and the $\mathrm{HO}_{2}^{-}$processes entirely correspond in the potential regions of species $\mathrm{d}$ and $\mathrm{c}$. This fact suggests that $\mathrm{HO}_{2}^{-}$'sees' the same surface in both experimental situations and that this surface may be ' 100 '-Au covered by OH species. Actually, the mechanism by which the disproportionation of $\mathrm{HO}_{2}^{-}$is catalyzed by the presence of $\mathrm{OH}$ species on the surface is not known. The nature of the surface structure called 'adsorbed $\mathrm{OH}$ species' in the literature is not known either.

Fig. 9 shows, that the increment as the rotation rate increases of the $\mathrm{HO}_{2}^{-}$reduction current intensity on ' 100 '-Au from the onset of $\mathrm{HO}_{2}^{-}$'reduction' down to the potential of the maximum is smaller in the presence of $\mathrm{Pb}$ (II) than in its absence; the polarization curves for $\mathrm{O}_{2}$ reduction in this potential range follow the same trend (cf. Fig. 3(b)). Below the potential of the maximum, the observed decrease of the $\mathrm{HO}_{2}^{-}$reduction current intensity is slower on the ' 100 '-Au surface with adsorbed $\mathrm{Pb}(11)$ ('100'- $\mathrm{Au}+\mathrm{Pb}(\mathrm{II})(\mathrm{ads})$ ) than on '100'-Au. (cf. Fig. 9) and, again, the $\mathrm{O}_{2}$ reduction current intensity follows the same trend (cf. Fig. 3(b)). By comparison with what appears to happen on '100'-Au [1], these facts suggest that, on '100'$\mathrm{Au}+\mathrm{Pb}(\mathrm{II})(\mathrm{ads})$ (i) $\mathrm{O}_{2}$ is reduced only to $\mathrm{HO}_{2}^{-}$in the potential range of species $\mathrm{d}$ and $\mathrm{c}$; the measured current intensity depends on the fate of the produced $\mathrm{HO}_{2}^{-}$, (ii) $\mathrm{HO}_{2}^{-}$is disproportionated and the $\mathrm{O}_{2}$ produced is recycled, (iii) the disproportionation process is catalyzed by a surface $\mathrm{OH}$ species (which is perturbed by some adsorbed $\mathrm{HPbO}_{2}^{-}$), (iv) the disproportionation rate constant is lower in the potential range of species $\mathrm{d}$ and higher on the potential range of species c.

McIntyre described the disproportionation of $\mathrm{HO}_{2}^{-}$ catalyzed by surface $\mathrm{OH}$ species by Eqs. (2) and (3) [26]

$\mathrm{HO}_{2}^{-*}+\mathrm{AuOH} \longrightarrow \mathrm{OH}^{-}+\mathrm{AuO}_{2} \mathrm{H}$,
$\mathrm{AuO}_{2} \mathrm{H}+\mathrm{HO}_{2}^{-*} \longrightarrow \mathrm{AuOH}+\mathrm{O}_{2}^{*}+\mathrm{OH}^{-}$,

where $\left(^{*}\right)$ means vicinity of the electrode surface. He developed the following equations to quantitatively describe the limiting current intensity obtained when $\mathrm{O}_{2}$ is reduced by a regenerative mechanism involving $\mathrm{HO}_{2}^{-}$disproportionation according to Eqs. (2) and (3) and with total rate constant $K_{4}$ [26]

$$
\begin{aligned}
I_{\mathrm{L}}= & 2 F A Z_{1} C_{1} \omega^{0.5}+2 F A Z_{1} C_{1} \omega^{0.5}\left[K_{4} /\left(Z_{2} \omega^{0.5}\right.\right. \\
& \left.\left.+K_{4}\right)\right], \\
I_{\mathrm{L}}= & 4 F A Z_{1} C_{1} \omega^{0.5}-F A Z_{2}^{2} \omega / K_{4}[(1 \\
& \left.\left.\left.+4 Z_{1} C_{1} K_{4} / Z_{2}^{2} \omega^{0.5}\right)\right)^{0.5}-1\right],
\end{aligned}
$$

where $Z=0.62 D^{2 / 3} v^{-1 / 6}$ and subscripts 1 and 2 refer, respectively, to $\mathrm{O}_{2}$ and $\mathrm{HO}_{2}^{-}$. Depending on which of the two Eq. (2) or Eq. (3), is slower, disproportionation appears, respectively, either as a pseudo-first order (Eq. (4)) or a second order (Eq. (5)) reaction.

As mentioned above, the Levich plot at the potential of the current intensity maximum for $\mathrm{O}_{2}$ reduction on ' 100 '- $\mathrm{Au}$ in a solution containing $\mathrm{Pb}$ (II) curves down as the rotation rate increases (cf. Fig. 7). This plot was modelled by applying McIntyre's model and the values of $K_{4}$ that gave the best fit to the experimental values of the current intensity measured at the potential of the maximum $(750 \mathrm{mV})$ from the polarization curves in Fig. 3(b) assuming first- or second-order disproportionation, are shown in Table 1. First-order disproportionation and $K_{4}=6.7 \times 10^{-3} \mathrm{~cm} \mathrm{~s}^{-1}$ gave the best overall fit. For ' 100 '-Au in the absence of $\mathrm{Pb}(\mathrm{II})$, the disproportionation was also found to be first-order and, as expected from the above discussion, the calculated value of $K_{4}$ was higher $\left(=8.5 \times 10^{-3} \mathrm{~cm} \mathrm{~s}^{-1}\right)$. The agreement between experimental and calculated current intensity values is very good at the lower rotation rates both in the absence and in the presence of $\mathrm{Pb}(\mathrm{II})$. However, as the rotation rate increases above $16 \mathrm{~s}^{-1}$ the experimental values show a negative shift relatively to the calculated ones. This may be due to the fact that above $16 \mathrm{~s}^{-1}$ the rate constant $K_{\mathrm{D}}(2)=Z_{2} \omega^{0.5}$ for the diffusion of $\mathrm{HO}_{2}^{-}$to the solution bulk becomes significant relatively to $\mathrm{K}_{4}$ and, consequently, the amount of $\mathrm{HO}_{2}^{-}$disproportionated decreases. The deviations observed in experiments with ' 100 '-Au covered by a $0.3 \mu$-thick Nafion film in a $1 \mathrm{M}$ $\mathrm{NaOH}$ without $\mathrm{Pb}(\mathrm{II})$ were, in fact, significantly smaller than those observed on a bare '100'-Au surface [27].

Below the potential of the maximum, disproportionation of $\mathrm{HO}_{2}^{-}$by a pseudo first-order disproportionation was also found to occur on '100'$\mathrm{Au}+\mathrm{Pb}(\mathrm{II})(\mathrm{ads})$, but $K_{4}$ continuously decreases as the potential goes cathodic. At $550 \mathrm{mV}$, a value of 
Table 1

Experimental $I_{\mathrm{L}}$ vs. calculated $I_{\mathrm{L}}(\mathrm{in} \mu \mathrm{A})$ for 1 st- and 2 nd-order disproportionation of $\mathrm{HO}_{2}^{-}$on ' 100 '- $\mathrm{Au}+\mathrm{Pb}(\mathrm{ads})$

\begin{tabular}{|c|c|c|c|c|c|c|}
\hline \multirow[t]{2}{*}{ Rotation rate $\left(s^{-1}\right)$} & \multicolumn{3}{|l|}{$E=725 \mathrm{mV}$} & \multicolumn{3}{|l|}{$E=550 \mathrm{mV}$} \\
\hline & experimental $(\mu \mathrm{A})$ & 1 st order ${ }^{\mathrm{a}}$ & 2 nd order ${ }^{b}$ & experimental $(\mu \mathrm{A})$ & 1 st order $^{\mathrm{c}}$ & 2 nd order ${ }^{\mathrm{d}}$ \\
\hline 1 & 96 & 96 & 96 & 89 & 88 & 90 \\
\hline 2 & 133 & 131 & 133 & 120 & 119 & 124 \\
\hline 3 & 156 & 157 & 161 & 140 & 141 & 150 \\
\hline 4 & 176 & 178 & 185 & 160 & 159 & 171 \\
\hline 9 & 245 & 254 & 270 & 220 & 223 & 247 \\
\hline 16 & 305 & 323 & 352 & 276 & 282 & 319 \\
\hline 25 & 364 & 390 & 433 & 336 & 340 & 389 \\
\hline
\end{tabular}

${ }^{\mathrm{a}} K_{4}=6.7 \times 10^{-3} \mathrm{~cm} \mathrm{~s}^{-1} . \quad{ }^{\mathrm{b}} K_{4}=3.0 \times 10^{4} \mathrm{~cm}^{4} \mathrm{~mol}^{-1} \mathrm{~s}^{-1} . \quad{ }^{\mathrm{c}} K_{4}=3.0 \times 10^{-3} \mathrm{~cm} \mathrm{~s}^{-1} . \quad{ }^{\mathrm{d}} K_{4}=1.0 \times 10^{4} \mathrm{~cm}^{4} \mathrm{~mol}^{-1} \mathrm{~s}^{-1}$.

$K_{4}=3.0 \times 10^{-3} \mathrm{~cm} \mathrm{~s}^{-1}$ was calculated; in this case, the negative shift of the experimental values is much smaller (cf. Table 1 and Fig. 7). In agreement with that reported in Ref. [1], in the absence of $\mathrm{Pb}(\mathrm{II})$ and at the same potential a true first order disproportionation [26] was found to occur (cf. Fig. 7).

The following mechanism

$$
\mathrm{HO}_{2}^{-} \leftrightarrow \mathrm{HO}_{2}^{-}\left(^{*}\right)
$$

$\mathrm{HO}_{2}^{-}\left(^{*}\right) \longrightarrow \frac{1}{2} \mathrm{O}_{2}\left(^{*}\right)+\mathrm{OH}^{-}$,

where Eq. (7) is the sum of Eqs. (4) and (5), also assumes that the process of $\mathrm{HO}_{2}^{-}$'reduction' on '100'$\mathrm{Au}+\mathrm{Pb}(\mathrm{II})$ (ads) in $1 \mathrm{M} \mathrm{NaOH}$ occurs in the potential region of species $\mathrm{d}$ and $\mathrm{c}$ through the disproportionation of the $\mathrm{HO}_{2}^{-}$that diffuses into the vicinity of the electrode; the produced $\mathrm{O}_{2}$ is then reduced back to $\mathrm{HO}_{2}^{-}$. If the reduction of $\mathrm{O}_{2}$ to $\mathrm{HO}_{2}^{-}$is reversible below the potential of the maximum and both the rate constant for this reduction $\left(K_{2}\right)$ and $K_{4}$ do not change appreciably in the Tafel potential range, this mechanism predicts the observed Tafel slope of $-30 \mathrm{mV}$ $\operatorname{dec}^{-1}$.

\subsubsection{Potential range of $\mathrm{Pb}(\mathrm{II})$ upd}

The reduction of $\mathrm{HO}_{2}^{-}$on the ' 100 '-Au surface covered with adsorbed $\mathrm{Pb}$ atoms (' 100 '- $\mathrm{Au}+\mathrm{Pb}$ (ads)) is significantly dependent on their different states of adsorption. The formation of the first structure of the underpotential-deposited lead causes the decrease of the $\mathrm{HO}_{2}^{-}$reduction current intensity to have an halt (cf. Fig. 10); the rapid decrease of this current intensity as the rotation rate increases means that $\mathrm{HO}_{2}^{-}$disproportionation still occurs, although with a smaller rate constant than that occurring at higher potentials. The decrease of the $\mathrm{HO}_{2}^{-}$reduction current intensity goes on when the second $(\approx 450 \mathrm{mV})$ and the third structure $(\approx 300 \mathrm{mV}$ ) of $\mathrm{Pb}$ atoms form; by $\approx 250 \mathrm{mV}$, the reduction current intensities for ' 100 '- $\mathrm{Au}+\mathrm{Pb}$ (ads) and for ' 100 '-Au are indistinguishable and very small.
However, the polarization curve for $\mathrm{O}_{2}$ reduction on ' 100 ' $-\mathrm{Au}+\mathrm{Pb}(\mathrm{ads})$ do not follow this overall decrease of the $\mathrm{HO}_{2}^{-}$reduction current intensity. Instead (cf. Fig. 3(b)), below the onset of lead upd the $\mathrm{O}_{2}$ reduction the current intensity increases continuously (following the increase of the adatoms coverage) from a level corresponding to 3.7 electrons per $\mathrm{O}_{2}$ molecule

(a)

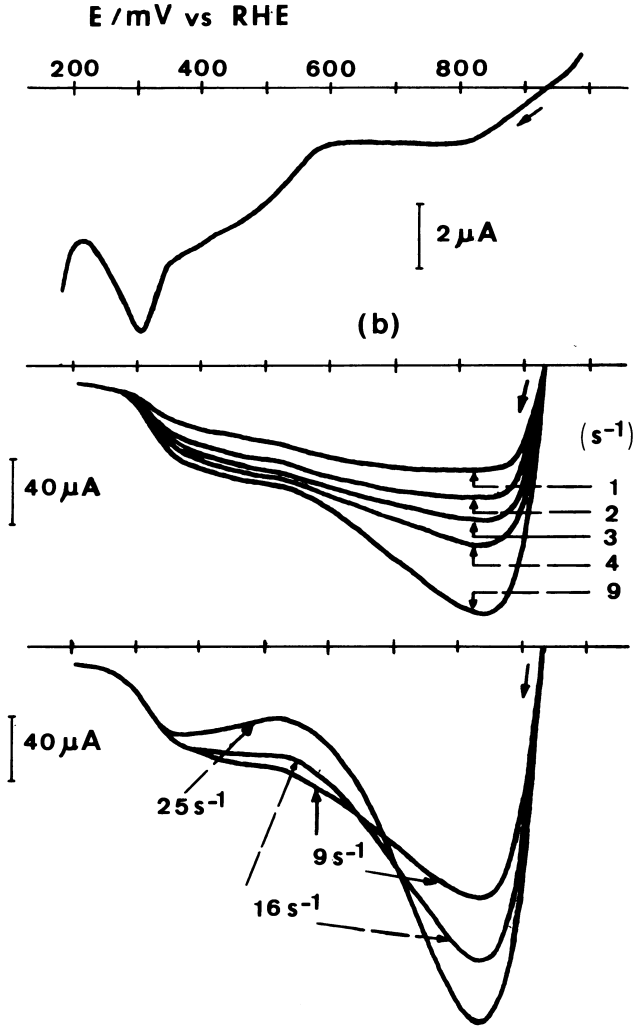

Fig. 10. Cathodic current intensities recorded on '100'-Au in argon-saturated $1 \mathrm{M} \mathrm{NaOH}+\mathrm{Pb}$ (II) without (a) and with (b) $1.5 \mathrm{mM} \mathrm{HO}_{2}^{-}$, scan rates (a) $20 \mathrm{mV} \mathrm{s}^{-1}$, (b) $10 \mathrm{mV} \mathrm{s}^{-1}$. 
at $550 \mathrm{mV}$ to the 4-electron level at $250 \mathrm{mV}$; however, the surface does not show any significant ability to reduce or disproportionate $\mathrm{HO}_{2}^{-}$in that potential range. It appears therefore that, below $550 \mathrm{mV}$, the $\mathrm{HO}_{2}^{-}$produced during the reduction of $\mathrm{O}_{2}$ adsorbs on the ' 100 '- $\mathrm{Au}+\mathrm{Pb}$ surface in such a way that it is reduced to $\mathrm{OH}^{-}$before it desorbs and diffuses to the solution bulk.

As mentioned in Section 3.2, although the polarization curves for $\mathrm{O}_{2}$ reduction show a current intensity plateau below $250 \mathrm{mV}$, the intercepts of the K-L lines, yet small, do not cross the origin in this potential range and the points of the corresponding Levich plots show an increasingly negative shift relative to the 4electron Levich lines as the rotation rate increases. Therefore, it appears that, below $250 \mathrm{mV}$, part of the current intensity is due to an activation-controlled process; this process may be the very slow chemical disproportionation of some of the $\mathrm{HO}_{2}^{-}$.

\section{Conclusions}

The electrochemistry of the '100'-Au surface in a deaerated, alkaline solution containing $\mathrm{Pb}$ (II) that this paper reports and discusses, differs considerably from that reported in the literature for the (100) crystallographic orientation of gold in the same experimental conditions. As a result, the way how the lead-modified ' 100 '-Au 'sees' the $\mathrm{O}_{2}$ molecule is also significantly different from that reported for the (100) gold face.

These facts suggest that there are no significant (100) spots on ' 100 '-Au and that this surface is structurally different from the (100) plane. The only common aspect of the electrochemical behavior of the (100) and the ' 100 '-Au surfaces appears to be the ability to adsorb $\mathrm{OH}^{-}$with total charge transfer in the potential range of 750 to $950 \mathrm{mV}$.

\section{Acknowledgements}

This work was carried out under the PRAXIS/2/2.1/ QI/193/94 project grant.

\section{References}

[1] C. Paliteiro, Electrochim. Acta 39 (1994) 1633.
[2] J. Brooker, P.A. Christensen, A. Hamnett, R. He, C. Paliteiro, Farad. Discuss. 94 (1992) 339.

[3] A. Hamelin, J. Lipkowski, J. Electroanal. Chem. 171 (1984) 317.

[4] A. Hamelin, J. Electroanal. Chem. 165 (1984) 167.

[5] R.R. Adzic, A.V. Tripkovic, N.M. Markovic, J. Electroanal. Chem. 114 (1980) 37.

[6] J.D.E. McIntyre, W.F. Peck, in: J.D.E. McIntyre, M.J. Weaver, E.B. Yeager (Eds.), The Chemistry and Physics of Electrocatalysis, The Electrochernical Society, Princeton, 1984.

[7] M. Alvarez-Rizatti, K. Jüttner, J. Electroanal. Chem. 144 (1983) 351.

[8] K. Jüttner, Electrochim. Acta 29 (1984) 1597.

[9] M. Alvarez, K. Jüttner, Electrochim. Acta 33 (1988) 33.

[10] D.A. Rand, R. Woods, J. Electroanal. Chem. 31 (1971) 29.

[11] D.D. Perrin, W.L.F. Almerego, D.D. Perrin, Purification of Laboratory Chemicals, Pergamon Press, Oxford, 1980.

[12] A. Hamelin, A. Katayama, G. Picq, P. Vennereau, J. Electroanal. Chem. 113 (1980) 293.

[13] Ju. Lurie, Handbook of Analytical Chemistry, Mir Publishers, Moscow, 1975.

[14] C. Paliteiro, Port. Electrochim. Acta 7 (1989) 471

[15] V.G. Levich, Physicochemical Hydrodynamics, PrenticeHall, Englewood Cliffs, NJ, 1962.

[16] K.E. Gubbins, R.D. Walker, J. Electrochem. Soc. 112 (1985) 459.

[17] E.W. Washburn, International Critical Tables, vol. 5, McGraw-Hill, New York, 1929.

[18] R.E. Davies, G.L. Horvath, C.W. Tobias, Electrochim. Acta 12 (1967) 287.

[19] F. Van den Brink, W. Visscher, E. Barendrecht, J. Electroanal. Chem. 172 (1984) 301.

[20] A. Hamelin, A. Katayama, J. Electroanal. Chem. 117 (1981) 221.

[21] N.A. Anastasijevic, S. Strbac, R.R. Adzic, J. Electroanal. Chem. 240 (1988) 239.

[22] S. Strbac, N.A. Anastasijevic, R.R. Adzic, J. Electroanal. Chem. 323 (1992) 179.

[23] R.R. Adzic, N.M. Markovic, J. Electroanal. Chem. 138 (1982) 443.

[24] A. Hamelin, M.J. Sottomayor, F. Silva, S.-C. Chang, M.J. Weaver, J. Electroanal. Chem. 295 (1990) 291.

[25] S. Strbac, A. Hamelin, R.R. Adzic, J. Electroanal. Chem. 362 (1993) 47.

[26] J.D. McIntyre, J. Phys. Chem. 71 (1967) 1196.

[27] C. Paliteiro, M.L. Pereira, in: A.J.L. Pombeiro, J.A. McCleverty (Eds.), Molecular Electrochemistry of Inorganic, Bioinorganic and Organometallic Compounds, Nato ASI Series, Kluwer Academic Publishers, Dordrecht, 1993, p. 405. 